\title{
A Hybrid Fuzzy Analytic Network Process Approach to the New Product Development Selection Problem
}

\author{
Chiuh-Cheng Chyu and Ying-Chieh Fang \\ Department of Industrial Engineering and Management, Yuan Ze University, 135 Yuan-Tung Road, Chung-Li 320, Taiwan \\ Correspondence should be addressed to Chiuh-Cheng Chyu; iehshsu@saturn.yzu.edu.tw
}

Received 27 February 2014; Revised 24 May 2014; Accepted 25 May 2014; Published 18 June 2014

Academic Editor: Changzhi Wu

Copyright (C) 2014 C.-C. Chyu and Y.-C. Fang. This is an open access article distributed under the Creative Commons Attribution License, which permits unrestricted use, distribution, and reproduction in any medium, provided the original work is properly cited.

\begin{abstract}
New product development selection is a complex decision-making process. To uphold their competence in competitive business environments, enterprises are required to continuously introduce novel products into markets. This paper presents a fuzzy analytic network process (FANP) for solving the product development selection problem. The fuzzy set theory is adopted to represent ambiguities and vagueness involved in each expert's judgment. In the proposed model, the fuzzy Kano method and fuzzy DEMATEL are employed to filter criteria and establish interactions among the criteria, whereas the SAM is applied to aggregate experts' opinions. Unlike the commonly used top-down relation-structuring approach, the proposed FANP first identifies the interdependence among the criteria and then the identified relationships are mapped to the clusters. This approach is more realistic, since the inner and outer relationships between criteria are simultaneously considered to establish the relationships among clusters. The proposed model is illustrated through a real life example, with a comparative analysis using modified TOPSIS and gray relation analysis in the synthesizing phase. The concluded results were approved by the case company. The proposed methodology not only is useful in the case study, but also can be generally applied in other similar decision situations.
\end{abstract}

\section{Introduction}

In order for a technology-based enterprise to uphold its competence in competitive business environments, one of its most challenging tasks is to continuously introduce novel products. Generally speaking, technology selection, customer satisfaction, and organization collaboration are three crucial factors for the success of a new product development. To sustain market competition with comparative advantages, an enterprise must invest in technological fields for developing various product alternatives under multiple criteria. Other than the technology aspect, evaluation should include economic and industrial criteria such as potential benefit, quality risk, technology development investment, and marketing cost, to determine the product most worthwhile for development. Furthermore, interdependent relationships may exist among such criteria in the real world. To address this challenging decision making issue, the research focuses on constructing a new product development selection model using hybrid evaluation techniques.

In business and engineering, new product development (NPD) is the complete process of introducing a new product to the market. Generally speaking, the NPD process usually comprises a number of stages. Such stages begin with idea generation and screening, market analysis, and technical implementation and end with commercialization and product pricing. This research focuses on the initial stage: the "NPD" of the NPD process [1], which includes generating and screening ideas. Multiple criteria decision making (MCDM) is an effective technique for this selection problem, since the MCDM can utilize group decision making (GDM) techniques to prioritize alternatives based on expert opinions for criteria highly relevant to the decision problem. The MCDM processes involve a series of steps: identifying the problems, constructing the preferences, evaluating the alternatives, and determining the best alternatives [2]. 
The GDM gathers further intellectual resources to support the decision. The resources available to the group include each individual member's competence, intuition, and knowledge. Usually, each expert has a distinct perception towards the problem, and therefore the integration technique of expert opinions is essential in GDM. Statistical methods and fuzzy methods are two appropriate solution approaches for the integration problem. In recent years, there are increasing research efforts in applying the linguistic aspect of fuzzy set theory to group decision making [3-5].

The analytic hierarchy process (AHP) is a comprehensive framework designed to cope with multicriterion decision problems. The AHP assumes that all elements in the same cluster are preferentially independent, and there is no relationship between clusters at the same or different levels. However, many decision problems cannot be structured hierarchically, because they involve interaction and dependence of higher level elements on a lower level element $[6,7]$. To overcome this difficulty, Saaty [7] proposed the analytic network process (ANP) to solve the dependence problem among alternatives or criteria. The ANP is an extension of the AHP, is based on concepts of Markov chains, and is nonlinear in structure [8]. This paper presents a hybrid fuzzy ANP-based approach to solve the NPD selection problem. In general, there are two approaches dealing with the integration of group decision making: (1) preintegration and (2) postintegration. The preintegration method integrates group opinions for each cluster element and then immediately defuzzifies the resulting fuzzy numbers. The postintegration method applies fuzzy set calculations during the process and then ranks the resulting fuzzy scores using defuzzification or other fuzzy ranking methods. Our study adopts the preintegration approach.

The proposed model uses a modified fuzzy Kano method (FKM) [9] to determine important criteria. The Kano model illustrates the relationship between customer satisfaction and product or service quality. Incorporating fuzzy set concepts with the Kano model enables an expert to express his opinions more flexibly and accurately. The DEMATEL with fuzzy concepts is applied to establish inner and outer relationships of the clusters and criteria in the ANP framework. Recently, the DEMATEL has been used to build ANP models [10-12]. The similarity aggregation method [13] is employed to aggregate expert opinions in applying the DEMATEL to establish the ANP structure and then to calculate the criteria weights in the decision network. Differing from commonly used topdown approach in structuring the dependency of ANP, the proposed method first identifies the interdependence among criteria, and then the identified relationships are mapped to upper level clusters. In the synthesizing stage, TOPSIS using weighted $L_{p}$ metrics [14] and gray relation analysis (GRA) [15] are used to evaluate alternatives and the results of the two methods are compared.

In the following, Section 2 provides a literature review; Section 3 describes the process of establishing the hybrid MCDM model; Section 4 presents the numerical results of a case study; Section 5 concludes the paper.

\section{Literature Review}

There are many studies in the literature using ANP to solve decision making problems. In two separate studies, Lee and Kim [16] applied ANP to prioritize interdependent information system projects. The studies [17-19] employed ANP to solve R\&D project selection problems. Hu et al. [20] also used ANP to evaluate the homestay industry in Northern Taiwan. Hybrid MCDM models are commonly used to solve complex decision problems. Mohanty et al. [18] presented a fuzzy ANP-based approach to solve R\&D selection problems, with a case study to illustrate the model. Shyur [21] combined ANP and a modified TOPSIS to evaluate and select the commercial-off-the-self (COTS) products for software development projects. In this study, ANP is used to obtain criteria weights, but not to evaluate the alternatives, so that the number of pairwise comparisons can be significantly reduced. The modified TOPSIS uses a newly defined weighted Euclidean distance to rank competing products, based on overall evaluation results for multiple criteria. Dağdeviren [22] also adopted the same approach to solve personnel selection problems in manufacturing systems. Hsu [23] presented a selection model combining ANP and GRA for independent media agencies, where GRA performs a role similar to TOPSIS in [21, 22]. Wu et al. [24] presented a hybrid MCDM that combines fuzzy Delphi method, ANP, and TOPSIS for supplier selection and applied the model to a real life situation. Azimi et al. [25] employed SWOT technique to build an ANP model and used TOPSIS to rank the strategies of mining sectors.

In practice, the perception of a decision maker is usually vague, fuzzy, or linguistic. Many decision makers are more confident in expressing their assessment or judgment in terms of fuzzy numbers. Fuzzy multiple criteria methods are often applied for selection problems when criteria values are imprecise or vague [27, 28]. Kahraman et al. [29] applied fuzzy AHP to select catering service companies in Italy. Kaboli et al. [30] applied fuzzy AHP to select the optimal and most preferable plant location for both investors and managers. Kahraman et al. [31] compared fuzzy axiomatic and fuzzy AHP methods to select the most appropriate renewable energy alternative for Turkey. Kang et al. [32] proposed a fuzzy ANP model which was structured based on interpretive structural modeling (ISM) for technology selection in NPD.

The technique for order preference by similarity to an ideal solution (TOPSIS) method was proposed by [33]. It is a useful technique in dealing with MCDM problems in practice. The main concept of TOPSIS is that the most preferred alternative should have the shortest distance from the positive ideal solution (PIS) and the longest distance from the negative ideal solution (NIS). The PIS is the solution that maximizes the benefit criteria and minimizes the cost criteria, while the NIS maximizes the cost criteria and minimizes the benefit criteria. TOPSIS helps decision maker(s) organize the problems to be solved and carry out analysis, comparisons, and ranking of the alternatives. In recent years, TOPSIS has been successfully applied to many areas, such as location selection and analysis [34, 35], product design [36], human 


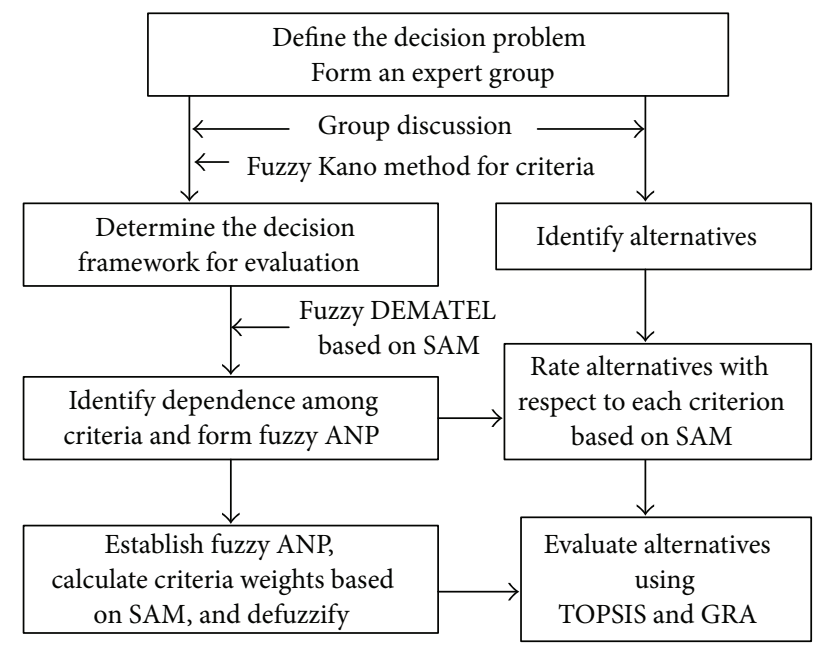

FIGURE 1: Proposed hybrid MCDM process.

resources management [37], manufacturing [38], and performance evaluation of ERP projects [39].

The Kano model was first developed by [40] to categorize the features of a product or service, based on how well they satisfy customers' needs. Compared to the traditional Kano model, the fuzzy Kano method allows the respondents to express their ideas in a more flexible and reasonable manner. The Kano model has been applied in new product development [26], new service creation [41], and logistics customer service [42].

\section{Proposed Model}

This section introduces the proposed hybrid MCDM. The general steps are described below and illustrated in Figure 1.

Step 1. Define the problem-what types of new product are to be considered? Organize a group comprising experts and decision makers from diverse and associated organizations, including R\&D, Marketing, Production, IT, Product Planning, Clients, and so forth. Initiate and categorize criteria based on the information in the literature and provided by group members. Identify the alternatives.

Step 2. Apply the fuzzy Kano method using weighted total frequency to determine the decision criteria, based on the weights assigned for the six attributes and a threshold value.

Step 3. Identify the dependence among criteria, and complete the ANP structure using fuzzy DEMATEL and SAM. The centroid method is used to defuzzify the strength of the integrated cause-and-effect influence calculated by the SAM. Set a threshold value for the influence strength to finalize the relation-structure of the criteria. The relationships among clusters are also to be determined based on the relationstructure of the criteria.
TABLE 1: Kano’s evaluation table.

\begin{tabular}{lccccc}
\hline \multirow{2}{*}{ Functional } & \multicolumn{5}{c}{ Dysfunctional } \\
& Like & Must-be & Neutral & Live-with & Dislike \\
\hline Like & $Q$ & $A$ & $A$ & $A$ & $O$ \\
Must-be & $R$ & $I$ & $I$ & $I$ & $M$ \\
Neutral & $R$ & $I$ & $I$ & $I$ & $M$ \\
Live-with & $R$ & $I$ & $I$ & $I$ & $M$ \\
Dislike & $R$ & $R$ & $R$ & $R$ & $Q$ \\
\hline
\end{tabular}

Source by [26].

Step 4. Apply the SAM to aggregate the expert opinions for pairwise comparison matrices of the FANP. Defuzzify the fuzzy numbers, confirm the consistency, and calculate the criteria weights using the method described in Section 3.4.

Step 5. Evaluate the alternatives by TOPSIS and GRA using the criteria weights obtained in Step 4. Compare the results of the two rating methods.

3.1. Fuzzy Kano Model (FKM). The FKM adopted for screening the criteria is based on [9] but uses a different evaluation standard. Thus, the Kano model illustrates the relationship between customer satisfaction and product or service quality. The model divides product or service features into five categories, as shown below.

(1) Must-be attributes: these attributes are considered to be necessary by customers. Their sufficiency will not result in higher satisfaction for customers, but insufficiency will dissatisfy customers.

(2) One-dimensional attributes: these attributes are "the more the better" and "the less the worse." The effects may only go in one direction.

(3) Attractive attributes: customers will feel more satisfaction as the performance of these attributes improves. However, customers will still deem them acceptable if they are not sufficient.

(4) Indifferent attributes: these attributes will not affect customer satisfaction, whether they are sufficient or not.

(5) Reverse attributes: these attributes have effects on customer satisfaction inverse to one-dimensional attributes; that is, "the more the worse" and "the less the better."

Kano et al. [40] used functional (positive) and dysfunctional (negative) questionnaires, which form a $5 \times 5$ evaluation table to determine distinct attributes. This is achieved by asking two questions.

(1) If the product/service provided to you functions well, how do you feel?

(2) If the product/service provided to you functions unsatisfactorily, how do you feel? 
TABLE 2: Traditional Kano's questionnaire (TKQ).

\begin{tabular}{|c|c|c|c|c|c|}
\hline TKQ & Like & Must-be & Neutral & Live-with & Dislike \\
\hline Functional & V & & & & \\
\hline Dysfunctional & & & & V & \\
\hline
\end{tabular}

TABLE 3: Fuzzy Kano’s questionnaire (FKQ).

\begin{tabular}{lccccc}
\hline FKQ & Like & Must-be & Neutral & Live-with & Dislike \\
\hline $\begin{array}{l}\text { Functional } \\
\text { Dysfunctional }\end{array}$ & 0.9 & 0.1 & & & \\
\hline
\end{tabular}

Table 1 shows Kano's evaluation table, where the symbol " $M$ " stands for "must-be," "O" for "one dimensional," " $A$ " for "attractive," "Q" for "questionable," "I" for "indifferent," and " $R$ " for reverse." Table 2 provides an answer sheet for the traditional Kano questionnaire (TKQ). If a respondent marks "like" for functional and "live-with" for dysfunctional, then the conclusion is " $A$ " from Table 1. Table 3 presents an example of the fuzzy Kano questionnaire (FKQ). The FKQ allows a respondent to give a fuzzy evaluation when he feels uncertain. Thus, the FKQ is superior to TKQ, since the former is more accurate in securing a respondent's authentic opinion. In the case of Table 3 , the $5 \times 5$ matrix is generated by $\left[\begin{array}{lllll}0.9 & 0.1 & 0 & 0 & 0\end{array}\right]^{T} \cdot\left[\begin{array}{lllll}0 & 0 & 0.1 & 0.4 & 0.5\end{array}\right]$, and the resulting value that corresponds to " $A$ " is $0.09+0.36=0.45$, to " $O$ " is 0.45 , to "I" is 0.05 , to " $M$ " is 0.05 , and to " $Q$ " is zero. If the significance classification level (also known as $\alpha$-cut) is set to 0.4 by the decision makers, then a value of 1 will be given to both " $A$ " and " $O$ " and 0 to the others.

The criteria screening process is illustrated as follows.

Step 1. For each criterion $C_{i j}$, calculate frequencies for each attribute $a$ based on the group's FKQ results, $\left\{F_{i j a}: a=\right.$ $O, A, M, I, R, Q\}$, where $F_{i j a}$ is the sum of "1" appearing in FKQ results of $N$ experts for $C_{i j}$.

Step 2. For each $C_{i j}$, calculate the weighted total frequency using formula (1):

$$
\begin{aligned}
W F_{i j}= & W_{o} \cdot F_{i j o}+W_{A} \cdot F_{i j A}+W_{M} \cdot F_{i j M} \\
& +W_{I} \cdot F_{i j I}+W_{R} \cdot F_{i j R}+W_{Q} \cdot F_{i j \mathrm{Q}} .
\end{aligned}
$$

Step 3. Compute $W F_{i j}$ for all criteria $C_{i j}$. If $W F_{i j} \geq p$, retain criterion $C_{i j}$; delete it if otherwise. The notation $p$ denotes the threshold value, which is set to the average of $W F_{i j}$ for all criteria in our study; that is, $p=\sum W F_{i j} / K^{\prime}$, if there are a total of $K^{\prime}$ criteria in the preliminary decision framework.

The FKM in this paper evaluates the importance level of a criterion based on weighted total frequency, which is different from commonly used maximum frequency. This modification can avoid biased cases and produce an objective and compromised screening solution. For example, if a criterion's FKQ result has a frequency of 5 for " $O$," 4 for " $A$,"
5 for " $M$," but 6 for " $I$ " and 0 for both " $R$ " and " $Q$," then this criterion will be classified as " $I$ " using the maximum frequency standard. However, this does not appear to be a good judgment since the total positive frequency of the three positive attributes is much greater than that of "I."

3.2. Similarity Aggregation Method (SAM). SAM [13] is a method for aggregating individual fuzzy opinions into a group fuzzy consensus opinion. The SAM procedure is summarized as follows. Let $\widetilde{R}_{n}=\left(L_{n}, M_{n}, U_{n}\right)$ represent the opinion of expert $E_{n}, n=1, \ldots, N$. The agreement degrees of experts $E_{n}$ and $E_{m}$ are defined as the following area ratio:

$$
S_{n m}=\frac{\operatorname{area}\left(\widetilde{R}_{n} \cap \widetilde{R}_{m}\right)}{\operatorname{area}\left(\widetilde{R}_{n} \cup \widetilde{R}_{m}\right)} .
$$

Note that $S_{n m}=0$ if $L_{m}>U_{n}$ or $L_{n}>U_{m}$. After all agreement degrees of the experts are measured, we can construct a symmetric agreement matrix (AM):

$$
\mathrm{AM}=\left[\begin{array}{cccc}
1 & S_{12} & \ldots & S_{1 N} \\
S_{21} & 1 & \ldots & S_{2 N} \\
\vdots & \vdots & \vdots & \vdots \\
S_{N 1} & S_{N 2} & \ldots & 1
\end{array}\right]
$$

The average agreement degree of expert $E_{n}(n=1, \ldots, N)$ is given by

$$
A\left(E_{n}\right)=\frac{1}{N-1} \sum_{m=1, m \neq n}^{N} S_{n m}
$$

The relative agreement degree of expert $E_{n}$ using (4) is

$$
\operatorname{RAD}_{n}=\frac{A\left(E_{n}\right)}{\sum_{m=1}^{N} A\left(E_{m}\right)}, \quad n=1, \ldots, N .
$$

If the relative importance of expert $E_{n}$ 's professional status is considered, then the consensus degree coefficient of expert $E_{n}$ can be defined as follows:

$$
\mathrm{CDC}_{n}=\lambda \cdot u_{n}+(1-\lambda) \cdot \mathrm{RAD}_{n}, \quad n=1, \ldots, N,
$$

where $0 \leq \lambda \leq 1$ and $u_{n}$ is the normalized relative importance of expert $E_{n}$, which is assigned according to expert $E_{n}$ 's professional status. The $\lambda$ value is used to compromise professional status and relative agreement degree of the $N$ experts. Therefore, the overall fuzzy number that results from combining experts' opinions to reach a consensus can be defined as follows:

$$
\widetilde{R}=\sum_{n=1}^{N}\left(\mathrm{CDC}_{n} \cdot \widetilde{R}_{n}\right)
$$

Our case study takes $\lambda=0$, which implies that all experts are equally important and their professional statuses are not considered. 
TABLE 4: Linguistic expression of criteria weights and alternative ratings.

\begin{tabular}{lll}
\hline Intensity of fuzzy scale & Linguistic variables for relative weights of criteria & Linguistic variables for performance values of alternatives \\
\hline$\widetilde{1}=(1,1,1)$ & Equally important & Extremely low \\
$\widetilde{3}=(2,3,4)$ & Moderately important & low \\
$\widetilde{5}=(4,5,6)$ & Strongly important & medium \\
$\widetilde{7}=(6,7,8)$ & Very strongly important & high \\
$\widetilde{9}=(9,9,9)$ & Extremely strongly important & Extremely high \\
$\widetilde{2}, \widetilde{4}, \widetilde{6}, \widetilde{8}$ & Intermediate values between two adjacent judgments; $\widetilde{2}=(1,2,3), \widetilde{4}=(3,4,5), \widetilde{6}=(5,6,7), \widetilde{8}=(7,8,9)$ \\
\hline
\end{tabular}

3.3. Fuzzy DEMATEL. The Decision Making Trial and Evaluation Laboratory (DEMATEL) method, developed by the Science and Human Affairs Program of the Battelle Memorial Institute of Geneva between 1972 and 1976, was used for researching and solving complicated and intertwined problems $[43,44]$. This methodology can confirm the interdependence among the criteria and reflect the relationship between the causes and effects of the criteria into an intelligent structural model $[12,45]$. The DEMATEL method is briefly described as follows.

Step 1. Calculate the initial direct-relation matrix.

Each expert $E_{n}$ is asked to specify the direct influence of one criterion $i$ over another criterion $j$ and vice versa. We denote the fuzzy direct influence given by expert $E_{n}$ as $\left\{\tilde{z}_{i j n} \mid i, j=1, \ldots, K, i \neq j, n=1, \ldots, N\right\}$, using a scale of fuzzy integers ranging from $\widetilde{0}$ to $\widetilde{4}$. The symbol $K$ is the total number of criteria. These fuzzy integers correspond to "little influence," "slight influence," "influence," "high influence," and "very high influence," respectively. They are defined as $\widetilde{0}=(0,0,1), \tilde{1}=(0,1,2), \widetilde{2}=(1,2,3), \widetilde{3}=(2,3,4)$, and $\tilde{4}=(3,4,4)$. The SAM technique is applied to aggregate the $N$ opinions, which results in $\widetilde{z}_{i j}=\left(L_{i j}, M_{i j}, U_{i j}\right)$. Each aggregated fuzzy number $\widetilde{z}_{i j}$ will then be defuzzified using the centroid method $\bar{z}_{i j}=\left(L_{i j}+M_{i j}+U_{i j}\right) / 3$. Thus, the initial direct influence matrix $\bar{Z}=\left\{\bar{z}_{i j}\right\}$ is obtained by pairwise comparisons and SAM procedure.

Step 2. Normalize the direct influence matrix $\bar{Z}$.

The normalized direct-relation matrix $\bar{D}$ is obtained by (8), in which all principal diagonal elements are zero. Consider

$$
\begin{aligned}
& \bar{D}=s \cdot \bar{Z} ; \quad 0<s \leq \sup ; \\
& \sup =\operatorname{Min}\left(\frac{1}{\max _{1 \leq i \leq K} \sum_{j=1}^{K}\left|z_{i j}\right|}, \frac{1}{\max _{1 \leq j \leq K} \sum_{i=1}^{K}\left|z_{i j}\right|}\right),
\end{aligned}
$$

where $\lim _{m \rightarrow \infty} \bar{D}^{m}=\{0\}$.

Step 3. Derive the total influence matrix $\bar{T}=\left\{\bar{t}_{i j}\right\}$. Consider

$$
\bar{T}=\bar{D} \cdot(I-\bar{D})^{-1}
$$

where $I$ is identity matrix.
Step 4. Set a threshold value $\alpha$ to obtain a truncated total influence matrix $\bar{T}^{\alpha}$ and produce an ANP structure based on the impact-diagraph-map relationships in $\bar{T}^{\alpha}$. If $\bar{T}^{\alpha}$ shows outer relationships among criteria belonging to different clusters (aspects), then these clusters will also be considered to be interrelated.

Setting an appropriate threshold value will help management make decisions efficiently and effectively. If all causeand-effect information in $\bar{T}$ is used for the impact-directmap, the ANP will be too complex for decision making. However, if the threshold is set to a higher standard, then $\bar{T}^{\alpha}$ might be a scarce matrix. In such a situation, using row sums of $\bar{T}^{\alpha}$ to normalize the elements in $\bar{T}^{\alpha}$ and then applying the normalized matrix to modulate the relative weights of criteria may not be able to reflect the authentic opinions of the experts. Hence, it would be more appropriate to consult with the experts to obtain the relative influential strengths of related criteria with respect to each criterion.

3.4. Fuzzy ANP. To calculate the cluster (or aspect) and criteria weights, the FANP requires each expert to compare the clusters and criteria in the whole decision framework, so that a supermatrix is formed through pairwise comparisons. A nine-level fuzzy scale shown in the first two columns of Table 4 is adopted to obtain experts' opinions. Similarly, columns 1 and 3 of Table 1 will be used for rating alternatives described in Section 3.5. In the calculation process, SAM is applied to aggregate the $N$ experts' assessments for each cell of pairwise comparison matrices. The centroid method is used to defuzzify the aggregated fuzzy values, and then the row geometric mean method is applied to obtain the relative weights of each cell in each comparison matrix.

The general form of the supermatrix is $\mathbf{W}=\left\{W_{i j}\right\}, i, j=$ $1, \ldots, M$, where $M$ is the total number of clusters in the ANP. $W_{i j}=\left\{w_{r s}\right\}, r=1, \ldots,\left|C_{i}\right|$ and $s=1, \ldots,\left|C_{j}\right|$, where $\left|C_{i}\right|$ is the number of elements in clusters $C_{i}$ and $C_{j}$, respectively. $w_{r s}$ is the normalized relative weight of element $r$ with respect to element $s$. Note that $\sum_{r} w_{r s}=1$, for $s=1, \ldots,\left|C_{j}\right|$. Since there is usually interdependence among clusters, the elements in a supermatrix column may add up to more than one. The supermatrix columns must be normalized to unity to make it stochastic. The final priority weights, which account for element interactions, are derived by continuously self-multiplying the transpose of the supermatrix until the transposed matrix converges. Saaty [7] 
suggested assigning equal values to normalize each column and obtain the weighted (i.e., stochastic) supermatrix.

Yang et al. [46] used row sum to normalize the elements of $\bar{T}^{\alpha}$ and to obtain a matrix S. Afterwards, a weighted (normalized) supermatrix is obtained via the following matrix calculation, $\mathbf{S} \cdot \mathbf{W}$. The limiting criteria weights can then be obtained by computing the weighted supermatrix for a sufficiently large number $n$. Shen et al. [47] built an ANP framework based on the total influence matrix $\bar{T}$, which will produce inner relationships among criteria within each cluster and outer relationships among criteria belonging to different clusters. Then, criteria weights were appraised for each submatrix with inner relationships (i.e., in the same aspect) and with outer relationships (i.e., cross different aspects). Thus, an unweighted supermatrix is constructed. The weighted supermatrix was acquired by assigning equal values to each submatrix so that each column sums to one, as suggested by Saaty [7]. Finally, the limiting criteria weights can be obtained using the Markov chain theory. Tamura and Akazawa [48] employed the total influence matrix $\bar{T}$ to modulate the relative criteria weights $\underline{w}_{c}$ using the formula $(I+\bar{T}) \cdot \underline{w}_{c}$, where $I$ is identity matrix.

This paper considers two methods for calculating the criteria weights of the ANP created by DEMATEL. Method 1 modulates the relative weights of both aspects and criteria by multiplying the interrelation weight matrix once, whereas Method 2 computes the criteria weights based on limiting supermatrix. Similar to Yang et al. [46], our ANP framework was built using $\bar{T}^{\alpha}$, but in our study the interrelation weight matrix was generated using pairwise comparisons based on the opinions of the experts.

It should be noted that the limiting supermatrix method may not be appropriate for certain types of ANP networks. An example is a hierarchical ANP with interrelations among elements on the same level but no feedback relations for elements on different levels. For such an ANP network, the limiting criteria weights will be independent of the initial relative weights of the criteria and the aspects, according to the Markov chain theory. In addition, some limiting criteria weights will be zero if there are one-directional impacts in the ANP network. Furthermore, some criteria weights may be overappraised due to adding effects of direct and indirect influences. Our research adopts Method 1, which adjusts the criteria weights by considering direct influence.

3.5. Evaluating the Alternatives. Two methods are applied to rate the overall scores of alternatives: (1) TOPSIS using weighted $L_{p}$ metrics and (2) GRA. Both rating methods use positive ideal solution (PIS) and negative ideal solutions (NIS), but their calculation formulae are different.

The following presents the modified TOPSIS procedure.

Step 1. Construct a decision matrix $D$.

Let $A=\left\{a_{1}, a_{2}, \ldots, a_{\mathrm{Q}}\right\}$ be a set of $Q$ alternatives; $C=\left\{C_{1}, C_{2}, \ldots, C_{K}\right\}$ is a set of $K$ criteria; a matrix $\left\{x_{q k}^{n} \mid\right.$ $q=1, \ldots, Q ; k=1, \ldots, K\}$ denotes the rating score of expert $E_{n}$ on alternative $q$ with respect to criterion $k$, $q=1, \ldots, Q ; k=1, \ldots, K$. Moreover, the relative criteria weights are $\left(v_{1}, v_{2}, \ldots, v_{K}\right)$. Apply geometric mean method to aggregate the $N$ experts' rating scores as in (10) and obtain the decision matrix $D=\left\{x_{q k}\right\}$. Consider

$$
x_{q k}=\left(\prod_{n=1}^{N} x_{q k}^{n}\right)^{1 / N}, \quad q=1, \ldots, Q ; k=1, \ldots, K .
$$

Step 2. Normalize the evaluation matrix $D$.

$$
r_{q k}=\frac{x_{q k}}{\sqrt{\sum_{q=1}^{Q} x_{q k}^{2}}}, \quad q=1, \ldots, Q ; k=1, \ldots, K .
$$

Step 3. Calculate the PIS and NIS.

After normalization, all $r_{i j}$ 's are the larger the better. Therefore,

$$
r_{k}^{*}=\max _{q=1, \ldots, Q} r_{q k}, \quad r_{k}^{-}=\min _{q=1, \ldots, Q} r_{q k}, \quad k=1, \ldots, K .
$$

Step 4. Calculate the distances to PIS (denoted $S_{q}^{+}$) and to NIS (denoted $S_{q}^{-}$) for alternative $q$ :

$$
\begin{aligned}
& S_{q}^{-}=\left(\sum_{k=1}^{K} v_{k} \cdot\left|r_{q k}-r_{k}^{-}\right|^{2}\right)^{1 / 2}, \\
& S_{q}^{+}=\left(\sum_{k=1}^{K} v_{k} \cdot\left|r_{k}^{*}-r_{q k}\right|^{2}\right)^{1 / 2}, \quad q=1, \ldots, Q .
\end{aligned}
$$

Step 5. Rank the alternatives.

Calculate the ratio

$$
R_{q}=\frac{S_{q}^{-}}{\left(S_{q}^{+}+S_{q}^{-}\right)}
$$

Afterwards, rank the alternatives based on $R_{q}$ values in decreasing order. The larger the value $R_{q}$, the better the alternative $q$.

The GRA has the same procedures for Step 1 as the modified TOSPSIS.

Step 2. Normalize the decision matrix $D$.

For benefit criteria, $r_{q k}=\left(x_{q k}-x_{k}^{-}\right) /\left(x_{k}^{*}-x_{k}^{-}\right)$.

For cost criteria, $r_{q k}=\left(x_{k}^{*}-x_{q k}\right) /\left(x_{k}^{*}-x_{k}^{-}\right)$. Clearly, the PIS is $r_{k}^{*}=1$, and the NIS is $r_{k}^{-}=0, k=1, \ldots, K$.

Step 3. Calculate the distance to PIS using $\Delta_{q k}=1-r_{q k}$. The gray relation coefficient (GRC) of alternative $q$ with respect to criterion $k$ is: $\gamma_{q k}=\xi /\left(\Delta_{q k}+\xi\right)$, where $\xi$ is the distinguishing coefficient and usually takes a value of 0.5 for objective purposes.

Step 4. Calculate the rating score $R_{q}$ for alternative $q$ and rank the alternatives:

$$
R_{q}=\sum_{k=1}^{K} v_{k} \cdot \gamma_{q k}, \quad q=1, \ldots, Q .
$$




\section{A Case Study}

Medical display monitors (MDMs) have been extensively used by medical organizations in recent years. The technological requirements of MDMS are higher than those of display monitors used for general purposes, but their gross profit margins are larger as well. Color calibration device (CCD) is a key component in the performance of medical display monitor (MDM). During the diagnosis and treatment process, MDMs must provide precise and stable images to assist doctors in treating their patients effectively and efficiently. The CCD provides measurement and correction functions for MDM to achieve high quality performance, including high resolution, steady luminous intensity and gray scale, and accurate color temperature. Therefore, CCD development is essential for MDM manufacturers.

The following describes the model implementation, which has been specified in Section 3. Step 1 includes "defining the problem," "forming a group comprising experts and decision makers," and "identifying alternatives."

The purpose of the case study is to build a hybrid MCDM model for selecting the best CCD to develop for a company. The case company is a subsidiary of a well-established international LCD producer in Taiwan. Thus, the company's relations and corporate support, including local hospitals and large medical centers, are its main assets. In the case study, ten experts and managers from diverse organizations in the company, such as R\&D, IT, Marketing, and Product Planning, were invited to join the group. Their opinions were collected for building the FANP model and calculating the criteria weights. In addition to the expert group, ten product-related sales agents were invited to appraise the alternatives with respect to each criterion.

The expert group proposed three types of CCD for development. The key features of the three alternatives are described as follows:

$\mathrm{A}_{1}$ : Front sensor-size: $18 \times 10 \mathrm{~mm}$; weight: $30 \mathrm{~g}$; built-in USB; automatic control; technical difficulty: moderate; current market share: $30 \%$; precision degree: $15 \%$; applicable MDM: 19-27 inch; investment: 100,000 USD; estimated selling price: 1,000 USD; warranty: 3 years.

$\mathrm{A}_{2}$ : Color sensor-size: $68 \times 41 \mathrm{~mm}$; weight: $140 \mathrm{~g}$; external USB; manual control; technical difficulty: low; current market share: 60\%; precision degree: 5\%; applicable MDM: 19-60 inch; investment: 60,000 USD; estimated selling price: 300 USD; warranty: 1 year.

$\mathrm{A}_{3}$ : Swing sensor-size: $117 \times 29 \times 96 \mathrm{~mm}$; weight: 160 g; external USB; automatic control; technical difficulty: high; current market share: $10 \%$; precision degree: 10\%; applicable MDM: 19-27 inch; investment: 150,000 USD; estimated selling price: 1,200 USD; warranty: 2 years.

A selection of the three alternatives will indicate the competitive advantages that the company currently possesses and which marketing strategies the company should adopt.
TABLE 5: Criterion frequencies of fuzzy Kano model and weighted total frequency.

\begin{tabular}{lccccccc}
\hline$W_{(M \sim Q)}$ & 0.8 & 1 & 0.6 & -1 & -1 & 0 & Avg. 7.493 \\
& $M$ & $O$ & $A$ & $I$ & $R$ & $Q$ & $W F_{i j}$ \\
\hline$C_{11}$ & 2 & 5 & 4 & 0 & 0 & 0 & 9 \\
$C_{12}$ & 5 & 4 & 1 & 0 & 0 & 0 & 8.6 \\
$C_{13}$ & 2 & 8 & 0 & 0 & 0 & 0 & 9.6 \\
$C_{14}$ & 3 & 3 & 5 & 0 & 0 & 0 & 8.4 \\
$C_{21}$ & 3 & 6 & 1 & 0 & 0 & 0 & 9 \\
$C_{22}$ & 3 & 4 & 4 & 1 & 0 & 0 & 7.8 \\
$C_{23}$ & 3 & 6 & 2 & 0 & 0 & 0 & 9.6 \\
$C_{24}$ & 4 & 4 & 3 & 1 & 0 & 0 & 8 \\
$C_{31}$ & 3 & 6 & 1 & 1 & 0 & 0 & 8 \\
$C_{32}$ & 1 & 7 & 2 & 1 & 0 & 0 & 8 \\
$C_{33}$ & 4 & 4 & 2 & 0 & 0 & 0 & 8.4 \\
\hline
\end{tabular}

From the company's standpoint, each alternative has its advantage and disadvantage. The technology threshold to successfully develop alternative $A_{1}$ is moderate, and thus the development risk is controllable. The built-in USB feature will be the competitive advantage in the market. The technological task of alternative $A_{2}$ is relatively easy. Therefore, its development risk is low, and the new product based on $A_{2}$ can be introduced to market within a short time. Since the development risk of $\mathrm{A}_{2}$ is low, there will be many competitors, and low product price will be critical to the success of the market introduction of $\mathrm{A}_{2}$. Finally, alternative $\mathrm{A}_{3}$ is technically difficult and has a high development risk and low probability of success. However, if successful, $\mathrm{A}_{3}$ will be the most beneficial, as the company will become a pioneer of CCD technology field, and the high selling price will generate high profit.

Step 2 is to apply fuzzy Kano method to determine the decision framework, using weights assigned for the six attributes.

The preliminary decision framework considers three aspects and fifteen criteria $[17,18,26,32,49,50]$. After the modified FKM was applied, eleven criteria are considered for the problem. Table 5 shows the FKQ results of the group for the eleven criteria, where each criterion has a weighted frequency greater than 7.493, which is the average of the initial fifteen criteria. In order to utilize the modified FKM, preprocessing is performed to assign the weights of the six quality attributes. Three attributes, $(M, A, O)$, are regarded as positive elements, whereas the other three attributes, $(R$, $I, Q)$, are considered to be undetermined or negative. By observing the characteristics of these attributes in a twodimensional Kano model and after a discussion with the group, a weight vector for the attributes is obtained as follows: $\left(W_{O}, W_{A}, W_{M}, W_{I}, W_{R}, W_{Q}\right)=(1,0.6,0.8,-1,-1,0)$. This assignment is conservative as it stresses the negative effects -1 for attributes $I$ and $R$, but 0.8 for attribute $M$ and 0.6 for attribute $A$. The expert group assigns the highest weight for "O" because this attribute evaluates the product performance with either positive or negative effects; a less weight for " $M$ " because it is a necessity for every new product alternative; 
TABLE 6: Initial direct matrix $\bar{D}$.

\begin{tabular}{lcccccccccccc}
\hline Criteria & $C_{11}$ & $C_{12}$ & $C_{13}$ & $C_{14}$ & $C_{21}$ & $C_{22}$ & $C_{23}$ & $C_{24}$ & $C_{31}$ & $C_{32}$ & $C_{33}$ \\
\hline$C_{11}$ & 0 & 0.082 & 0.077 & 0.089 & 0.097 & 0.104 & 0.096 & 0.069 & 0.062 & 0.098 & 0.093 \\
$C_{12}$ & 0.103 & 0 & 0.077 & 0.104 & 0.112 & 0.076 & 0.060 & 0.109 & 0.109 & 0.084 & 0.117 \\
$C_{13}$ & 0.112 & 0.092 & 0 & 0.063 & 0.086 & 0.109 & 0.085 & 0.111 & 0.103 & 0.097 & 0.115 \\
$C_{14}$ & 0.077 & 0.116 & 0.076 & 0 & 0.070 & 0.072 & 0.097 & 0.096 & 0.114 & 0.102 & 0.048 \\
$C_{21}$ & 0.109 & 0.088 & 0.097 & 0.115 & 0 & 0.094 & 0.103 & 0.084 & 0.100 & 0.095 & 0.115 \\
$C_{22}$ & 0.076 & 0.077 & 0.072 & 0.109 & 0.100 & 0 & 0.063 & 0.068 & 0.121 & 0.077 & 0.097 \\
$C_{23}$ & 0.097 & 0.103 & 0.078 & 0.114 & 0.090 & 0.078 & 0 & 0.069 & 0.071 & 0.042 & 0.098 \\
$C_{24}$ & 0.104 & 0.101 & 0.089 & 0.103 & 0.087 & 0.089 & 0.113 & 0 & 0.097 & 0.068 & 0.097 \\
$C_{31}$ & 0.093 & 0.076 & 0.081 & 0.075 & 0.076 & 0.097 & 0.103 & 0.088 & 0 & 0.102 & 0.092 \\
$C_{32}$ & 0.079 & 0.084 & 0.124 & 0.111 & 0.056 & 0.084 & 0.076 & 0.076 & 0.072 & 0 & 0.072 \\
$C_{33}$ & 0.056 & 0.090 & 0.061 & 0.078 & 0.079 & 0.076 & 0.115 & 0.084 & 0.106 & 0.103 & 0 \\
\hline
\end{tabular}

TABLE 7: Initial total influence matrix $\bar{T}$ and truncated $\bar{T}^{\alpha}$ with $\alpha=0.8$.

\begin{tabular}{lccccccccccc}
\hline Criteria & $C_{11}$ & $C_{12}$ & $C_{13}$ & $C_{14}$ & $C_{21}$ & $C_{22}$ & $C_{23}$ & $C_{24}$ & $C_{31}$ & $C_{32}$ & $C_{33}$ \\
\hline$C_{11}$ & 0.688 & 0.770 & 0.710 & $\mathbf{0 . 8 1 1}$ & 0.743 & 0.765 & 0.783 & 0.720 & 0.785 & 0.756 & $\mathbf{0 . 8 0 0}$ \\
$C_{12}$ & $\mathbf{0 . 8 4 6}$ & 0.759 & 0.769 & $\mathbf{0 . 8 9 1}$ & $\mathbf{0 . 8 1 6}$ & $\mathbf{0 . 8 0 5}$ & $\mathbf{0 . 8 2 1}$ & $\mathbf{0 . 8 1 6}$ & $\mathbf{0 . 8 9 4}$ & $\mathbf{0 . 8 0 9}$ & $\mathbf{0 . 8 8 7}$ \\
$C_{13}$ & $\mathbf{0 . 8 6 7}$ & $\mathbf{0 . 8 5 7}$ & 0.711 & $\mathbf{0 . 8 7 2}$ & $\mathbf{0 . 8 0 9}$ & $\mathbf{0 . 8 4 7}$ & $\mathbf{0 . 8 5 5}$ & $\mathbf{0 . 8 3 0}$ & $\mathbf{0 . 9 0 3}$ & $\mathbf{0 . 8 3 2}$ & $\mathbf{0 . 9 0 1}$ \\
$C_{14}$ & 0.764 & $\mathbf{0 . 8 0 2}$ & 0.712 & 0.732 & 0.723 & 0.741 & 0.787 & 0.746 & $\mathbf{0 . 8 3 1}$ & 0.762 & 0.765 \\
$C_{21}$ & $\mathbf{0 . 8 8 3}$ & $\mathbf{0 . 8 7 3}$ & $\mathbf{0 . 8 1 6}$ & $\mathbf{0 . 9 3 4}$ & 0.746 & $\mathbf{0 . 8 5 1}$ & $\mathbf{0 . 8 8 8}$ & $\mathbf{0 . 8 2 5}$ & $\mathbf{0 . 9 1 9}$ & $\mathbf{0 . 8 4 8}$ & $\mathbf{0 . 9 1 8}$ \\
$C_{22}$ & 0.755 & 0.762 & 0.702 & $\mathbf{0 . 8 2 3}$ & 0.742 & 0.668 & 0.754 & 0.717 & $\mathbf{0 . 8 3 2}$ & 0.738 & $\mathbf{0 . 8 0 0}$ \\
$C_{23}$ & 0.760 & 0.772 & 0.693 & $\mathbf{0 . 8 1 3}$ & 0.722 & 0.727 & 0.680 & 0.705 & 0.777 & 0.694 & 0.787 \\
$C_{24}$ & $\mathbf{0 . 8 4 2}$ & $\mathbf{0 . 8 4 7}$ & 0.773 & $\mathbf{0 . 8 8 5}$ & 0.792 & $\mathbf{0 . 8 1 0}$ & $\mathbf{0 . 8 5 9}$ & 0.712 & $\mathbf{0 . 8 7 8}$ & 0.788 & $\mathbf{0 . 8 6 5}$ \\
$C_{31}$ & 0.784 & 0.775 & 0.723 & $\mathbf{0 . 8 1 1}$ & 0.735 & 0.770 & $\mathbf{0 . 8 0 1}$ & 0.746 & 0.737 & 0.770 & $\mathbf{0 . 8 1 1}$ \\
$C_{32}$ & 0.740 & 0.751 & 0.730 & $\mathbf{0 . 8 0 5}$ & 0.688 & 0.728 & 0.744 & 0.706 & 0.772 & 0.647 & 0.759 \\
$C_{33}$ & 0.727 & 0.762 & 0.682 & 0.786 & 0.713 & 0.726 & 0.785 & 0.719 & $\mathbf{0 . 8 0 6}$ & 0.745 & 0.699 \\
\hline
\end{tabular}

the smallest weight for " $A$ " with the purpose of keeping a conservative and optimistic attitude toward this new product development problem.

The three aspects $[17,18,49,50]$ and the criteria within each aspect $[17,18,26,32,49,50]$ are as follows:

technical capability $\left(P_{1}\right)-C_{11}$ : technology patent, $C_{12}$ : product accreditation, $C_{13}$ : customization capacity and $C_{14}: R \& D$ capability;

marketing environment $\left(P_{2}\right)-C_{21}$ : product profitability, $C_{22}$ : competitiveness, $C_{23}$ : consumer preference and $C_{24}$ : brand image;

organizational management $\left(P_{3}\right)-C_{31}$ : relations and corporate support, $C_{32}$ : integration ability, and $C_{33}$ : marketing capability.

Step 3 employs fuzzy DEMATEL and SAM to identify the dependence among criteria. The resulting cause-and-effect among criteria is mapped to aspects for deriving relationstructures. Then the integrated cause-and-effect strength, calculated by the SAM, is defuzzified via the centroid method. Table 6 displays the defuzzified initial direct matrix $\bar{D}$, and Table 7 shows the total influence matrix $\bar{T}$. The ANP network was built using the truncated $\bar{T}^{\alpha}$. In order to reduce network complexity and consider only major effects, a high threshold value of $\alpha=0.8$ is adopted to map $\bar{T}^{\alpha}$ onto the hierarchical framework. All the underlined boldface values are above 0.8 and will be applied to establish the relation-structure of the criteria and the aspects. The outcome indicates that the three aspects interact with each other, and the resulting structure of the ANP with corresponding supermatrix is shown in Figure 2. Note that matrix $W_{10}$ is 3 by 1 , and it denotes the relative importance of the three aspects with respect to the goal. Matrix $W_{11}$ is 3 by 3 , which gives the relative weights due to interdependence among the three aspects. Since all three aspects have inner-relations criteria and outer-relations criteria, the evaluation of relative importance or influential strengths will include each aspect itself. Matrix $W_{21}$ is 11 by 3 and each column indicates the relative importance of the criteria with respect to their aspect. Finally, matrix $W_{22}$ is 11 by 11 and each column represents the relative weights due to interrelations among criteria. The elements of $W_{11}$ and $W_{22}$ are derived based on pairwise comparisons through consultations with experts.

Liou and Chuang [10] studied the outsourcing provider selection problem and developed a hybrid MCDM model 


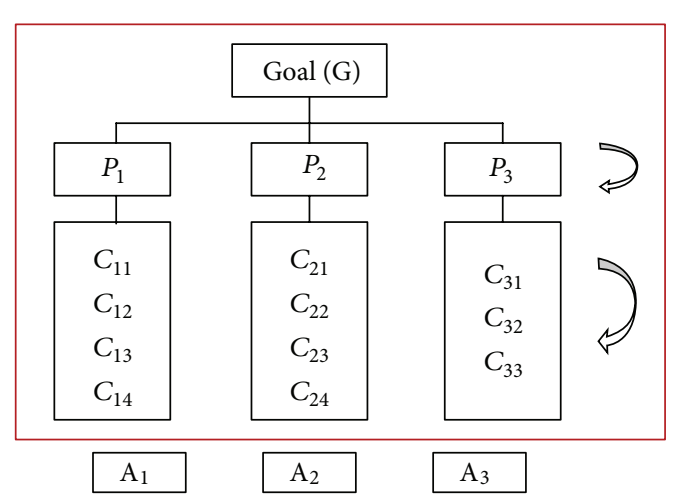

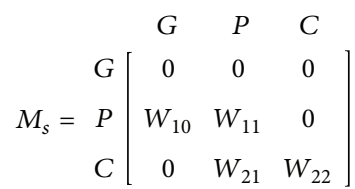

Unweighted supermatrix

$$
M_{w}=P\left[\begin{array}{ccc}
G & P & C \\
0 & 0 & 0 \\
W_{10} & W_{11} / 2 & 0 \\
0 & W_{21} / 2 & W_{22}
\end{array}\right]
$$

Weighted supermatrix

FIGURE 2: ANP structure with alternatives and corresponding supermatrices.

\begin{tabular}{|c|c|c|c|c|c|}
\hline & $P_{1}$ & $P_{2}$ & $P_{3}$ & RGM & $W_{10}$ \\
\hline$P_{1}$ & $\mathbf{1}(1,1,1)$ & $\mathbf{0 . 7 2 3}(0.702,0.719,0.749)$ & $4.128(3.144,4.128,5.112)$ & 1.440 & 0.402 \\
\hline$P_{2}$ & $\mathbf{1 / 0 . 7 2 3}(1 / 0.749,1 / 0.719,1 / 0.702)$ & $\mathbf{1}(1,1,1)$ & $3.872(2.903,3.871,4.841)$ & 1.749 & 0.488 \\
\hline$P_{3}$ & $\mathbf{1 / 4 . 1 2 8}(1 / 5.112,1 / 4.128,1 / 3.144)$ & 1/3.872 $(1 / 4.841,1 / 3.871,1 / 2.903)$ & $\mathbf{1}(1,1,1)$ & 0.397 & 0.111 \\
\hline
\end{tabular}

TABLE 8: Pairwise comparisons and relative weights of aspects against goal.

$\lambda_{\max }$ : 3.017; CI: 0.008; RI: 0.580; CR: 0.014 .

TABLE 9: Interdependence weight matrix $W_{11}$

\begin{tabular}{lccc}
\hline$W_{11}$ & $P_{1}{ }^{*}$ & $P_{2}$ & $P_{3}$ \\
\hline$P_{1}$ & $0.704^{*}$ & 0.438 & 0.662 \\
$P_{2}$ & $0.204^{*}$ & 0.484 & 0.133 \\
$P_{3}$ & $0.092^{*}$ & 0.078 & 0.204 \\
\hline
\end{tabular}

consisting of DEMATEL, ANP, and VIKOR to prioritize the alternatives. In their model, the DEMATEL builds a relationstructure among criteria, the ANP determines the relative criteria weights that take into account dependence and feedback, and the VIKOR ranks the alternatives. A similar approach was adopted to solve the supplier selection problem [11] and technology selection for organic LED product [12].

The purpose of Step 4 is to derive reliable criteria weights for the ANP from Step 3, using pairwise comparisons and the SAM procedure. Table 8 presents the calculation results of the relative importance for the three aspects with respect to the goal. First, the SAM is applied to the expert group in order to obtain the aggregated fuzzy relative importance ratios, which are triangular fuzzy numbers. Then the centroid method is used to defuzzify these fuzzy numbers. Finally, the row geometric mean (RGM) method is employed to obtain the weights of three aspects with respect to the goal. The size of matrix $W_{10}$ is 3 by 1 . By applying similar procedures, the interdependence weight matrix of $W_{11}$ is obtained. Table 9 presents matrix $W_{11}$, and Table 10 shows the calculation process of obtaining the interdependence weights of $P_{1}$ within three aspects. Table 11 displays the matrix $W_{21}$, which represents the relative weights of the criteria with respect to their own aspect. These weights are obtained through the same calculation procedure.
Table 12 presents matrix $W_{22}$, which provides the interdependence weights among the criteria. These weights are obtained via the truncated matrix $\bar{T}^{\alpha}$. For example, it can be observed that criterion $C_{11}$ is influenced by criteria $C_{12}, C_{13}$, $C_{21}$, and $C_{24}$ from $\bar{T}^{\alpha}$. Thus, the relative influential strengths of these criteria on criterion $C_{11}$ are assessed using pairwise comparisons given by the experts, and then their assessments are aggregated using the SAM technique.

In Section 3.4, two methods were introduced to calculate the relative criteria weights. When the limiting supermatrix approach (Method 2) is used, the resulting criteria weights will be independent of the initial relative weights of the criteria and the aspects (i.e., $W_{10}$ and $W_{21}$ ). It is the result from Markov chain theory. In addition, the limiting supermatrix approach may not be appropriate if the chain is not irreducible (not all criteria influence each other). In such a situation, some criteria will have zero limiting weights. In addition, some criteria weights may be overrated due to counting the weight based on direct influence and all indirect influences. It is more reasonable to use Method 1, which modulates the relative weights based on direct influence. Table 13 shows the relative weights of aspects and criteria using Method 1. Table 14 presents the limiting relative weights of criteria by applying Method 2 on the matrix $M_{w}$ in Figure 2. The following describes the two calculation methods for criteria weights.

Method 1: the formula for calculating global criteria weights $\underline{w}_{c}$ is $\left(\left(W_{22} \cdot W_{21}\right) \cdot\left(W_{11} \cdot W_{10}\right)\right)$, which yields $\underline{w}_{c}=$ $(0.024,0.186,0.222,0.033,0.326,0.024,0.017,0.098,0.042$, $0.023,0.006)$. The adjusted aspect weights are $\left(W_{11} \cdot W_{10}\right)=$ $(0.570,0.333,0.098)$; the unadjusted global criteria weights are $\left(W_{21} \cdot\left(W_{11} \cdot W_{10}\right)\right)=(0.070,0.117,0.113,0.103,0.139,0.117$, $0.164,0.028,0.029,0.032,0.037)$; the adjusted criteria weights are $\underline{w}_{c}$ as shown above. 
TABLE 10: Pairwise comparisons and relative dependence weights of $P_{1}$ within aspects.

\begin{tabular}{|c|c|c|c|c|c|}
\hline & $P_{1}$ & $P_{2}$ & $P_{3}$ & RGM & $W^{*}$ \\
\hline$P_{1}$ & $\mathbf{1}(1,1,1)$ & $4.152(3.314,4.147,4.996)$ & $6.360(5.411,6.360,7.309)$ & 2.978 & $0.704^{*}$ \\
\hline$P_{2}$ & 1/4.152 $(1 / 4.996,1 / 4.147,1 / 3.314)$ & $\mathbf{1}(1,1,1)$ & $2.646(1.767,2.646,3.525)$ & 0.861 & $0.204^{*}$ \\
\hline$P_{3}$ & $\mathbf{1 / 6 . 3 6 0}(1 / 7.309,1 / 6.360,1 / 5.411)$ & $\mathbf{1 / 2 . 6 4 6}(1 / 3.525,1 / 2.646,1 / 1.767)$ & $\mathbf{1}(1,1,1)$ & 0.390 & $0.092^{*}$ \\
\hline
\end{tabular}

$\lambda_{\text {max }}: 3.033$; CI: 0.017; RI: 0.580; CR: 0.029 .

TABLE 11: Weight matrix $W_{21}$.

\begin{tabular}{lccc}
\hline$W_{21}$ & $P_{1}$ & $P_{2}$ & $P_{3}$ \\
\hline$C_{11}$ & 0.173 & & \\
$C_{12}$ & 0.291 & & \\
$C_{13}$ & 0.281 & & \\
$C_{14}$ & 0.256 & 0.310 & \\
$C_{21}$ & & 0.262 & \\
$C_{22}$ & & 0.365 & \\
$C_{23}$ & & 0.063 & 0.301 \\
$C_{24}$ & & & 0.325 \\
$C_{31}$ & & 0.374 \\
$C_{32}$ & & & \\
$C_{33}$ & & & \\
\hline
\end{tabular}

Method 2: the limiting global criteria weights $\left(\underline{w}_{c}\right)^{T}=$ any column of $\lim _{n \rightarrow \infty}\left(\left(W_{22}\right)^{T}\right)^{n}=(0.005,0.187,0.323,0.034$, $0.408,0.004,0.004,0.024,0.006,0.005,0.001)$, which are independent of the submatrices $W_{10}, W_{11}$, and $W_{12}$.

As observed from $W_{22}$ in Table 12 , the criteria $C_{12}$ (Product accreditation), $C_{13}$ (Customization capacity), and $C_{21}$ (Relations and corporate support) are the most influential criteria, and their adjusted global weights are the weighted sum of their influenced criteria weights, increasing from $(0.117,0.113,0.103)$ to $(0.186,0.222,0.326)$ for Method 1 and to $(0.187,0.323,0.408)$ for Method 2. The global weights of $C_{12}, C_{13}$, and $C_{21}$ under AHP calculations $\left(W_{21} \cdot W_{10}\right)$ are $(0.117,0.113,0.151)$. However, the three criteria weights of Method 1 are smaller than those of Method 2 since Method 1 only includes direct influence effect but Method 2 covers both direct and indirect influence effects. On the other hand, criteria $C_{14}$ and $C_{33}$ impact the other criteria the least, their weights decrease from $(0.103,0.037)$ to $(0.033,0.006)$ for Method 1 and to $(0.034,0.001)$ for Method 2.

Method 1 will be appropriate for our hierarchical ANP framework, since each of $W_{10}, W_{11}$, and $W_{21}$ will have an impact on the final criteria weights to rate the alternatives.

The final step requires the 20 participants in Step 1 to appraise the performance of each alternative with respect to each criterion. The weighted TOPSIS and GRA described in Section 3.5 are employed to evaluate the three alternatives. The results are shown in Table 15. The elements of column $j$ under TOPSIS are the normalized scores $r_{q k}$ obtained by (11). The synthetized scores of the three alternatives are $R_{q}$ in (14), obtained through Steps 3-5 of the TOPSIS procedure in Section 3.5. The elements of column $j$ under GRA are the gray relation coefficient (GRC) $\gamma_{q k}$, and the synthetized scores are calculated using (15). Both methods lead to the same conclusion, regardless of which method is used to derive the criteria weights. The values within the parentheses are counted using Method 2. Alternative $A_{1}$ is the best choice for the case company, mainly because $A_{1}$ is most likely to generate high profits and obtain product accreditation. In addition, the color adjustment of $A_{1}$ is automatic, whereas the adjustments of $\mathrm{A}_{2}$ and $\mathrm{A}_{3}$ are semiautomatic. The major customers of the case company are medical organizations, where the medical staff are usually busy during business hours and may not constantly be able to keep CCO in the optimal condition. The medical staff generally prefer $A_{1}$ to the other two alternatives.

\section{Conclusions}

The medical display monitors (MDMs) are commonly used in medical service centers, and the industry has been growing rapidly in the past decades. Generally speaking, MDMs require more advanced technology than LCD monitors. Therefore, the profit margin is higher than the standard LCD monitors. The color calibration device is a crucial component for the functional quality of MDM. In this study, we present a hybrid multiple criteria decision model for selecting the most suitable new color calibration device for a company interested in the MDM market to develop. The case company is a subsidiary of a well-established international LCD producer. Thus, the company's relations and corporate support, including local hospitals and large medical centers, are its main assets.

The presented MCDM model consists of the following stages. (1) Apply fuzzy Kano model with weighted total frequency to screen important factors or criteria for the studied problem; compared to the mode frequency standard, the weighted total frequency is more objective and more likely to reach consensus and achieve a better screening solution. (2) Employ the DEMATEL and SAM to aggregate the group's opinions and recognize the interdependency among perspectives, as well as criteria, and thus produce the ANP framework; a strict threshold is adopted to generate cause-and-effect relationships among criteria and these relationships will in turn generate the interrelations among the aspects at the upper level. (3) Evaluate the ANP framework based on pairwise comparisons using SAM; apply two computation methods to calculate the relative weights: one based on direct influence and the other based on limiting supermatrix. (4) Rate three alternatives for each of the 11 criteria using weighted TOPSIS and GRA; select the best alternative based on the weighted sum with global criteria weights obtained from stage 3 . In this case study, it yields the same alternative rankings for any combination of the 
TABLE 12: Interdependence weights among criteria matrix $W_{22}$.

\begin{tabular}{|c|c|c|c|c|c|c|c|c|c|c|c|}
\hline & $C_{11}$ & $C_{12}$ & $C_{13}$ & $C_{14}$ & $C_{21}$ & $C_{22}$ & $C_{23}$ & $C_{24}$ & $C_{31}$ & $C_{32}$ & $C_{33}$ \\
\hline$C_{11}$ & & & & 0.133 & & & & & & & 0.122 \\
\hline$C_{12}$ & 0.151 & & & 0.086 & 0.396 & 0.326 & 0.385 & 0.587 & 0.126 & 0.706 & 0.113 \\
\hline$C_{13}$ & 0.302 & 0.345 & & 0.069 & 0.604 & 0.322 & 0.142 & 0.184 & 0.118 & 0.150 & 0.151 \\
\hline$C_{14}$ & & 0.178 & & & & & & & 0.105 & & \\
\hline$C_{21}$ & 0.287 & 0.388 & 1.000 & 0.084 & & 0.080 & 0.272 & 0.229 & 0.142 & 0.144 & 0.201 \\
\hline$C_{22}$ & & & & 0.090 & & & & & 0.152 & & 0.165 \\
\hline$C_{23}$ & & & & 0.118 & & & & & & & \\
\hline$C_{24}$ & 0.260 & 0.089 & & 0.116 & & 0.272 & 0.047 & & 0.167 & & 0.185 \\
\hline$C_{31}$ & & & & 0.145 & & & 0.153 & & & & 0.062 \\
\hline$C_{32}$ & & & & 0.158 & & & & & & & \\
\hline$C_{33}$ & & & & & & & & & 0.191 & & \\
\hline
\end{tabular}

TABLE 13: Modulated criteria weights by Method 1.

\begin{tabular}{|c|c|c|c|c|c|c|c|c|c|c|c|}
\hline Aspect & \multicolumn{4}{|c|}{$P_{1}$} & \multicolumn{4}{|c|}{$P_{2}$} & \multicolumn{3}{|c|}{$P_{3}$} \\
\hline Weight & \multicolumn{4}{|c|}{0.570} & \multicolumn{4}{|c|}{0.333} & \multicolumn{3}{|c|}{0.098} \\
\hline Criteria & $C_{11}$ & $C_{12}$ & $C_{13}$ & $C_{14}$ & $C_{21}$ & $C_{22}$ & $C_{23}$ & $C_{24}$ & $C_{31}$ & $C_{32}$ & $C_{33}$ \\
\hline Weight & 0.024 & 0.186 & 0.222 & 0.033 & 0.326 & 0.024 & 0.017 & 0.098 & 0.042 & 0.023 & 0.006 \\
\hline
\end{tabular}

TABLE 14: Criteria weights in the limiting supermatrix (Method 2).

\begin{tabular}{lcccccccccccc}
\hline & $C_{11}$ & $C_{12}$ & $C_{13}$ & $C_{14}$ & $C_{21}$ & $C_{22}$ & $C_{23}$ & $C_{24}$ & $C_{31}$ & $C_{32}$ & $C_{33}$ \\
\hline$C_{11}$ & 0.005 & 0.005 & 0.005 & 0.005 & 0.005 & 0.005 & 0.005 & 0.005 & 0.005 & 0.005 & 0.005 \\
$C_{12}$ & 0.187 & 0.187 & 0.186 & 0.187 & 0.187 & 0.187 & 0.185 & 0.187 & 0.188 & 0.187 & 0.187 \\
$C_{13}$ & 0.323 & 0.323 & 0.322 & 0.323 & 0.323 & 0.323 & 0.321 & 0.323 & 0.324 & 0.323 & 0.323 \\
$C_{14}$ & 0.034 & 0.034 & 0.034 & 0.034 & 0.034 & 0.034 & 0.034 & 0.034 & 0.034 & 0.034 & 0.034 \\
$C_{21}$ & 0.408 & 0.408 & 0.408 & 0.408 & 0.408 & 0.408 & 0.410 & 0.408 & 0.406 & 0.407 & 0.408 \\
$C_{22}$ & 0.004 & 0.004 & 0.004 & 0.004 & 0.004 & 0.004 & 0.004 & 0.004 & 0.004 & 0.004 & 0.004 \\
$C_{23}$ & 0.004 & 0.004 & 0.004 & 0.004 & 0.004 & 0.004 & 0.004 & 0.004 & 0.004 & 0.004 & 0.004 \\
$C_{24}$ & 0.024 & 0.024 & 0.024 & 0.024 & 0.024 & 0.024 & 0.024 & 0.024 & 0.024 & 0.024 & 0.024 \\
$C_{31}$ & 0.006 & 0.006 & 0.006 & 0.006 & 0.006 & 0.006 & 0.006 & 0.006 & 0.006 & 0.006 & 0.006 \\
$C_{32}$ & 0.005 & 0.005 & 0.005 & 0.005 & 0.005 & 0.005 & 0.005 & 0.005 & 0.005 & 0.005 & 0.005 \\
$C_{33}$ & 0.001 & 0.001 & 0.001 & 0.001 & 0.001 & 0.001 & 0.001 & 0.001 & 0.001 & 0.001 & 0.001 \\
\hline
\end{tabular}

TABLE 15: Ratings of three alternatives using weighted TOPSIS and GRA.

\begin{tabular}{|c|c|c|c|c|c|c|c|}
\hline \multirow{2}{*}{ Criteria } & \multirow{2}{*}{ Method 1 (2) Weight $\underline{w}_{c}$} & \multicolumn{3}{|c|}{ TOPSIS $\left(r_{q k}\right)$} & \multicolumn{3}{|c|}{$\operatorname{GRA}\left(\gamma_{q k}\right)$} \\
\hline & & $A_{1}$ & $\mathrm{~A}_{2}$ & $\mathrm{~A}_{3}$ & $A_{1}$ & $\mathrm{~A}_{2}$ & $\mathrm{~A}_{3}$ \\
\hline \multicolumn{8}{|l|}{$\overline{P_{1}}$} \\
\hline$C_{11}$ & $0.024(0.005)$ & 0.618 & 0.436 & 0.654 & 0.750 & 0.333 & 1.000 \\
\hline$C_{12}$ & $0.186(0.187)$ & 0.668 & 0.385 & 0.636 & 1.000 & 0.333 & 0.817 \\
\hline$C_{13}$ & $0.222(0.323)$ & 0.545 & 0.732 & 0.410 & 0.463 & 1.000 & 0.333 \\
\hline$C_{14}$ & $0.033(0.034)$ & 0.526 & 0.716 & 0.458 & 0.405 & 1.000 & 0.333 \\
\hline \multicolumn{8}{|l|}{$P_{2}$} \\
\hline$C_{21}$ & $0.326(0.408)$ & 0.694 & 0.438 & 0.571 & 1.000 & 0.333 & 0.510 \\
\hline$C_{22}$ & $0.024(0.004)$ & 0.467 & 0.599 & 0.650 & 0.333 & 0.642 & 1.000 \\
\hline $\mathrm{C}_{23}$ & $0.017(0.004)$ & 0.628 & 0.667 & 0.401 & 0.777 & 1.000 & 0.333 \\
\hline $\mathrm{C}_{24}$ & $0.098(0.024)$ & 0.691 & 0.529 & 0.492 & 1.000 & 0.381 & 0.333 \\
\hline \multicolumn{8}{|l|}{$P_{3}$} \\
\hline$C_{31}$ & $0.042(0.006)$ & 0.476 & 0.732 & 0.487 & 0.333 & 1.000 & 0.344 \\
\hline$C_{32}$ & $0.023(0.005)$ & 0.397 & 0.714 & 0.576 & 0.333 & 1.000 & 0.534 \\
\hline$C_{33}$ & $0.006(0.001)$ & 0.644 & 0.623 & 0.443 & 1.000 & 0.827 & 0.333 \\
\hline Synthetiz & & $0.706(0.673)$ & $0431(0.471)$ & $0.421(0.382)$ & $0.792(0.794)$ & $0.572(0.584)$ & $0.519(0.503)$ \\
\hline
\end{tabular}


rating alternative methods and the criteria weight calculation methods.

The proposed approach is useful in practice, as it aims to integrate several validated effective methods in an optimal manner, with necessary modifications on some stages of the decision process. This approach is illustrated through an empirical case. The concluded results were supported by the case company, and follow-up processes are ongoing. This outcome encourages us to believe that the developed model is highly suitable as a decision making tool for reaching decisions about new product development.

\section{Conflict of Interests}

The authors declare that there is no conflict of interests.

\section{Acknowledgments}

The authors would like to thank ChilinTech and Mr. M.C. Lin for their valuable support and assistance to this research work and are greatly encouraged by learning that the concluded results were approved by the company with follow-up actions under progress.

\section{References}

[1] P. Koen, G. Ajamian, R. Burkart et al., "Providing clarity and a common language to the 'fuzzy front end," Research Technology Management, vol. 44, no. 2, pp. 46-55, 2001.

[2] R. L. Keeney and H. Raiffa, Decisions with Multiple Objectives: Preferences and Value Tradeoffs, Wiley, New York, NY, USA, 1976.

[3] F. Herrera, E. Herrera-Viedma, and J. L. Verdegay, "A sequential selection process in group decision making with a linguistic assessment approach," Information Sciences, vol. 85, no. 4, pp. 223-239, 1995.

[4] M. H. Rasmy, S. M. Lee, W. F. Abd El-Wahed, A. M. Ragab, and M. M. El-Sherbiny, "An expert system for multiobjective decision making: application of fuzzy linguistic preferences and goal programming," Fuzzy Sets and Systems, vol. 127, no. 2, pp. 209-220, 2002.

[5] W. Pedrycz and M. Song, "Analytic Hierarchy process (AHP) in group decision making and its optimization with an allocation of information granularity," IEEE Transactions on Fuzzy Systems, vol. 19, no. 3, pp. 527-539, 2011.

[6] T. L. Saaty and M. Takizawa, "Dependence and independence: from linear hierarchies to nonlinear networks," European Journal of Operational Research, vol. 26, no. 2, pp. 229-237, 1986.

[7] T. L. Saaty, Decision Making with Dependence and Feedback: The Analytic Network Process, RWS publications, Pittsburgh, Pa, USA, 1996.

[8] T. L. Saaty, Decision Making for Leaders: The Analytic Hierarchy Process for Decisions in a Complex World, RWS publications, Pittsburgh, Pa, USA, 1999.

[9] Y.-C. Lee and S.-Y. Huang, "A new fuzzy concept approach for Kano's model," Expert Systems with Applications, vol. 36, no. 3, pp. 4479-4484, 2009.

[10] J. J. Liou and Y.-T. Chuang, "Developing a hybrid multi-criteria model for selection of outsourcing providers," Expert Systems with Applications, vol. 37, no. 5, pp. 3755-3761, 2010.
[11] J. L. Yang and G. Tzeng, "An integrated MCDM technique combined with DEMATEL for a novel cluster-weighted with ANP method," Expert Systems with Applications, vol. 38, no. 3, pp. 1417-1424, 2011.

[12] Y.-C. Shen, G. T. Lin, and G.-H. Tzeng, "Combined DEMATEL techniques with novel MCDM for the organic light emitting diode technology selection," Expert Systems with Applications, vol. 38, no. 3, pp. 1468-1481, 2011.

[13] H.-M. Hsu and C.-T. Chen, "Aggregation of fuzzy opinions under group decision making," Fuzzy Sets and Systems, vol. 79, no. 3, pp. 279-285, 1996.

[14] H.-S. Shih, H.-J. Shyur, and E. S. Lee, "An extension of TOPSIS for group decision making," Mathematical and Computer Modelling, vol. 45, no. 7-8, pp. 801-813, 2007.

[15] J.-L. Deng, "Grey entropy and grey target decision making," Journal of Grey System, vol. 22, no. 1, pp. 1-4, 2010.

[16] J. W. Lee and S. H. Kim, "Using analytic network process and goal programming for interdependent information system project selection," Computers and Operations Research, vol. 27, no. 4, pp. 367-382, 2000.

[17] E. E. Karsak, S. Sozer, and S. E. Alptekin, "Product planning in quality function deployment using a combined analytic network process and goal programming approach," Computers and Industrial Engineering, vol. 44, no. 1, pp. 171-190, 2003.

[18] R. P. Mohanty, R. Agarwal, A. K. Choudhury, and M. K. Tiwari, "A fuzzy ANP-based approach to R\&D project selection: a case study," International Journal of Production Research, vol. 43, no. 24, pp. 5199-5216, 2005.

[19] A. Agarwal, R. Shankar, and M. K. Tiwari, "Modeling the metrics of lean, agile and leagile supply chain: an ANP-based approach," European Journal of Operational Research, vol. 173, no. 1, pp. 211-225, 2006.

[20] Y.-C. Hu, J.-H. Wang, and R.-Y. Wang, "Evaluating the performance of Taiwan Homestay using analytic network Process," Mathematical Problems in Engineering, vol. 2012, Article ID 827193, 24 pages, 2012.

[21] H.-J. Shyur, "COTS evaluation using modified TOPSIS and ANP," Applied Mathematics and Computation, vol. 177, no. 1, pp. 251-259, 2006.

[22] M. Dağdeviren, "A hybrid multi-criteria decision-making model for personnel selection in manufacturing systems," Journal of Intelligent Manufacturing, vol. 21, no. 4, pp. 451-460, 2010.

[23] P.-F. Hsu, "Selection model based on ANP and GRA for independent media agencies," Quality and Quantity, vol. 46, no. 1, pp. 1-17, 2012.

[24] C.-M. Wu, C.-L. Hsieh, and K.-L. Chang, "A hybrid multiple criteria decision making model for supplier selection," Mathematical Problems in Engineering, vol. 2013, Article ID 324283, 8 pages, 2013.

[25] R. Azimi, A. Yazdani-Chamzini, M. M. Fouladgar, E. K. Zavadskas, and M. H. Basiri, "Ranking the strategies of mining sector through ANP and TOPSIS in a SWOT framework," Journal of Business Economics and Management, vol. 12, no. 4, pp. 670-689, 2011.

[26] K. Matzler and H. H. Hinterhuber, "How to make product development projects more successful by integrating Kano's model of customer satisfaction into quality function deployment," Technovation, vol. 18, no. 1, pp. 25-38, 1998.

[27] C. Kahraman, D. Ruan, and I. Doğan, "Fuzzy group decisionmaking for facility location selection," Information Sciences, vol. 157, no. 1-4, pp. 135-153, 2003. 
[28] T.-Y. Chou, C.-L. Hsu, and M.-C. Chen, "A fuzzy multi-criteria decision model for international tourist hotels location selection," International Journal of Hospitality Management, vol. 27, no. 2, pp. 293-301, 2008.

[29] C. Kahraman, U. Cebeci, and D. Ruan, "Multi-attribute comparison of catering service companies using fuzzy AHP: the case of Turkey," International Journal of Production Economics, vol. 87, no. 2, pp. 171-184, 2004.

[30] A. Kaboli, M. B. Aryanezhad, K. Shahanaghi, and I. Niroomand, "A new method for plant location selection problem: a fuzzyAHP approach," in Proceedings of the IEEE International Conference on Systems, Man, and Cybernetics (SMC '07), pp. 582-586, October 2007.

[31] C. Kahraman, I. Kaya, and S. Cebi, "A comparative analysis for multiattribute selection among renewable energy alternatives using fuzzy axiomatic design and fuzzy analytic hierarchy process," Energy, vol. 34, no. 10, pp. 1603-1616, 2009.

[32] H.-Y. Kang, A. H. Lee, C.-C. Chang, and M.-S. Kang, "A model for selecting technologies in new product development," Mathematical Problems in Engineering, vol. 2012, Article ID 358129, 17 pages, 2012.

[33] C.-L. Hwang and K. Yoon, Multiple Attribute Decision Making, Springer, New York, NY, USA, 1981.

[34] K. Yoon and C.-L. Hwang, "Manufacturing plant location analysis by multiple attribute decision making: part I-singleplant strategy," International Journal of Production Research, vol. 23, no. 2, pp. 345-359, 1985.

[35] D. Choudhary and R. Shankar, "An STEEP-fuzzy AHP-TOPSIS framework for evaluation and selection of thermal power plant location: a case study from India," Energy, vol. 42, no. 1, pp. 510$521,2012$.

[36] C. K. Kwong and S. M. Tam, "Case-based reasoning approach to concurrent design of low power transformers," Journal of Materials Processing Technology, vol. 128, no. 1-3, pp. 136-141, 2002.

[37] M.-F. Chen and G.-H. Tzeng, "Combining grey relation and TOPSIS concepts for selecting an expatriate host country," Mathematical and Computer Modelling, vol. 40, no. 13, pp. 14731490, 2004.

[38] A. S. Milani, A. Shanian, R. Madoliat, and J. A. Nemes, "The effect of normalization norms in multiple attribute decision making models: a case study in gear material selection," Structural and Multidisciplinary Optimization, vol. 29, no. 4, pp. 312318, 2005.

[39] Z. Hui-Ru and L. Na-Na, "A novel hybrid evaluation model for the performance of ERP project based on ANP and improved matter-element extension model," Mathematical Problems in Engineering, vol. 2013, Article ID 913212, 9 pages, 2013.

[40] N. Kano, N. Seraku, F. Takahashi, and S. Tsuji, "Attractive quality and must-be quality," The Journal of the Japanese Society for Quality Control, vol. 14, no. 2, pp. 39-48, 1984.

[41] S. Bhattacharyya and Z. Rahman, "Capturing the customer's voice, the centerpiece of strategy making: a case study in banking," European Business Review, vol. 16, no. 2, pp. 128-138, 2004.

[42] R. Florez-Lopez and J. M. Ramon-Jeronimo, "Managing logistics customer service under uncertainty: an integrative fuzzy Kano framework," Information Sciences, vol. 202, pp. 41-57, 2012.

[43] E. Fontela and A. Gabus, The DEMATEL Observer, Battelle Institute, Geneva Research Center, Geneva, Switzerland, 1976.

[44] J. N. Warfield, Societal Systems: Planning, Policy, and Complexity, World Scientific, River Edge, NJ, USA, 1976.
[45] G.-H. Tzeng, C.-H. Chiang, and C.-W. Li, "Evaluating intertwined effects in e-learning programs: a novel hybrid MCDM model based on factor analysis and DEMATEL," Expert Systems with Applications, vol. 32, no. 4, pp. 1028-1044, 2007.

[46] Y.-P. Yang, H.-M. Shieh, J.-D. Leu, and G.-H. Tzeng, "A novel hybrid MCDM model combined with DEMATEL and ANP with applications," International Journal of Operations Research, vol. 5, no. 3, pp. 160-168, 2008.

[47] Y.-C. Shen, G. T. Lin, and G.-H. Tzeng, "Combined DEMATEL techniques with novel MCDM for the organic light emitting diode technology selection," Expert Systems with Applications, vol. 38, no. 3, pp. 1468-1481, 2011.

[48] H. Tamura and K. Akazawa, "Structural modeling and systems analysis of uneasy factors for realizing safe, secure and reliable society," Journal of Telecommunications and Information Technology, vol. 3, pp. 64-72, 2005.

[49] L. M. Meade and A. Presley, "R\&D project selection using the analytic network process," IEEE Transactions on Engineering Management, vol. 49, no. 1, pp. 59-66, 2002.

[50] P. Fahrni and M. Spätig, "An application-oriented guide to R\&D project selection and evaluation methods," R\&D Management, vol. 20, no. 2, pp. 155-171, 1990. 


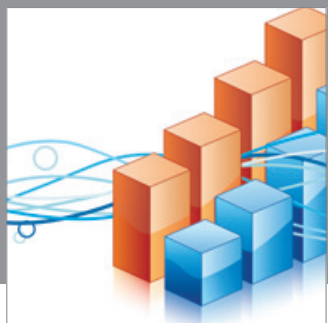

Advances in

Operations Research

mansans

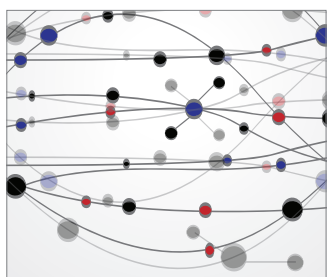

The Scientific World Journal
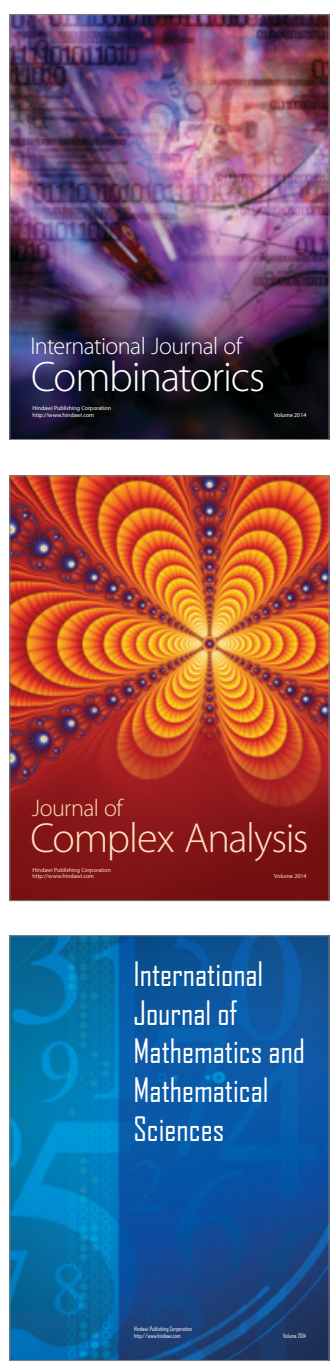
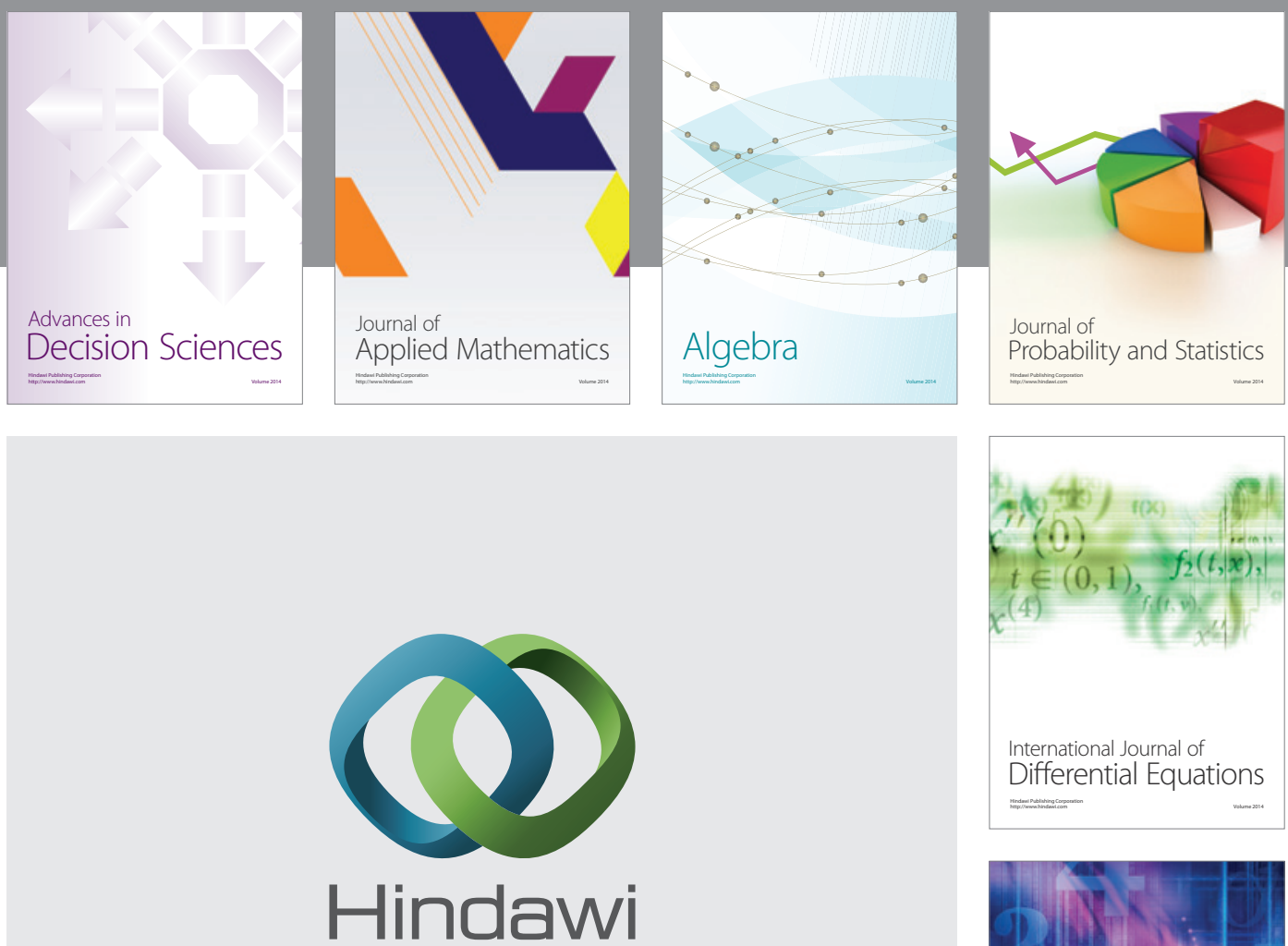

Submit your manuscripts at http://www.hindawi.com
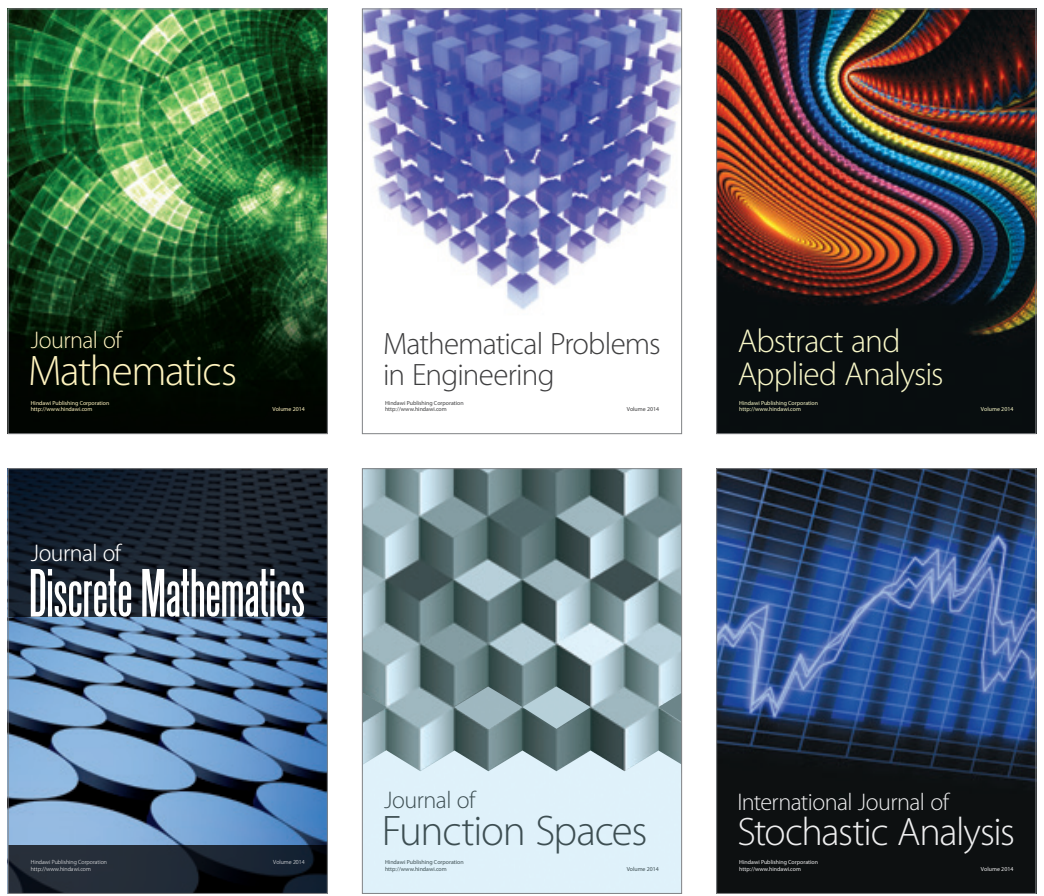

Journal of

Function Spaces

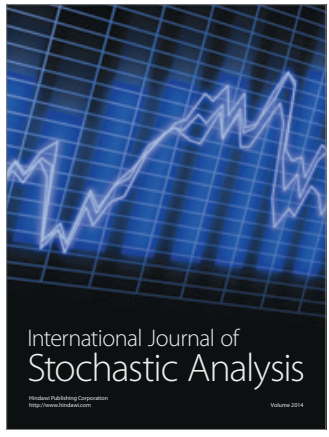

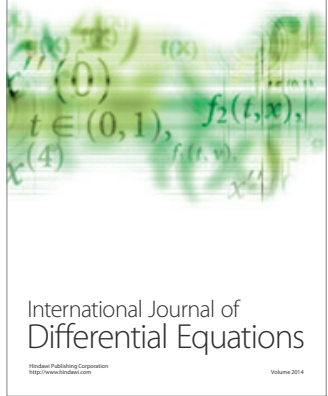
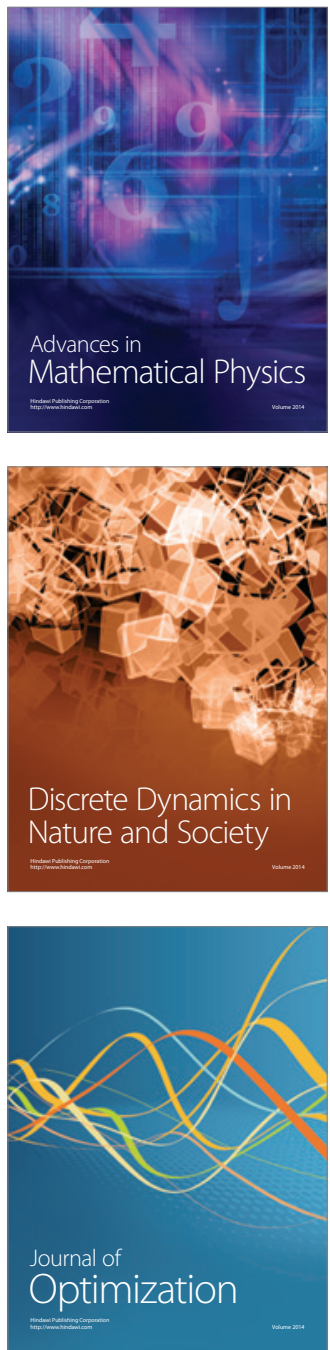